\title{
Cardiac Mathematical Models for Exercise Testing on Treadmill Ergometer
}

\author{
Milan Stork \\ Department of Applied Electronics \\ and Telecommunications/RICE \\ University of West Bohemia \\ Plzen, Czech Republic \\ stork@kae.zcu.cz
}

\author{
Jaroslav Novak \\ Department of Sports Medicine \\ Medical Faculty in Plzen \\ Charles University in Prague \\ Plzen, Czech Republic \\ novakj@1fp.cuni.cz
}

\author{
Pavel Broz \\ Department of Clinical Biochemistry \\ Medical Faculty in Plzen \\ Charles University in Prague \\ Plzen, Czech Republic \\ broz@fnplzen.cz
}

\begin{abstract}
Cardiac output (CO) is a key parameter in the assessment of cardiac function, and its measurement is fundamental to the diagnosis, treatment, and prognostic evaluation of all heart diseases. In this paper the linear and nonlinear models for noninvasive estimation of $\mathrm{CO}$ are presented. The estimation is based from short examination where parameters of subject were measured up to maximal load and from these parameters the CO and stroke volume (SV) were estimated for evaluation of cardiovascular performance of the subject. This approach was used for group of twenty marathon runners. Linear and nonlinear mathematical models and samples of measuring results are also presented.
\end{abstract}

Keywords- cardiac output; linear model; cubic model; non-invasive estimation; oxygen uptake; heart rate; stroke volume

\section{INTRODUCTION}

Cardiac output $(\mathrm{CO})$ is a measure of the amount of blood pumped by either ventricle. Until recently, cardiac output determination during exercise had been only possible through invasive methods, which were not practical in the clinical setting. In steady state, the outputs of both ventricles are the same. In a healthy adult male, cardiac output is approximately $5 \mathrm{l} / \mathrm{min}$ [1]. $C O$ can vary, however, according to the body's physiological needs; for example, a well-trained athlete, while exercising, can increase $C O$ to up to 30 $1 /$ min to increase the rate of transport of oxygen, nutrients, and wastes [2]. Abnormally low levels of cardiac output can also be an indication of pathology. $C O$ is one of the most important hemodynamic signals to measure in patients with compromised cardiovascular performance. There are many methods of monitoring the hemodynamic status of patients, both invasive and non-invasive, the most popular of which is thermodilution $[3,4,5]$. The one noninvasive method is based on monitor consists of a carbon dioxide sensor, a disposable air flow sensor

Milan Stork's participation was supported by Department of Applied Electronics and Telecommunications, University of West Bohemia, Plzen, Czech Republic and by the European Regional Development Fund and the Ministry of Education, Youth and Sports of the Czech Republic under the Regional Innovation Centre for Electrical Engineering (RICE), project No. LO1607 and by the Internal Grant Agency of University of West Bohemia in Plzen, the proiect SGS-2018-001 and a pulse oxymeter. The next method is thoracic electrical bioimpedance. The first derivative of the impedance waveform is related linearly to aortic blood flow. Changes in impedance correlate with stroke volume. The estimation of $C O$ via pulse contour analysis is an indirect method, since $C O$ is not measured directly, as with an electromagnetic flow probe, but is computed from a pressure pulsation on basis of a criterion or model $[6,7,8,9,10]$. All of the methods have their advantages and disadvantages, but thermodilution is the golden standard for critical patients, although it does entail many risks. The ideal system for cardiac output monitoring would be noninvasive, easy to use, reliable and possible used at rest and also during physical activity. The estimation based on heart rate $(H R)$ should be good, because $H R$ is easy and reliable measured also during the subject physical activity.

Because oxygen uptake $\left(\mathrm{VO}_{2}\right)$ is cardiac output times arteriovenous content difference, evaluation of cardiac output is usually included in its measurement. Measurement of $\mathrm{CO}$ and $\mathrm{VO}_{2}$ should correlate well in healthy subjects at rest as well as during exercise. Because both $\mathrm{HR}$ and volume of $\mathrm{VO}_{2}$ can be easily measured during standard incremental cardiopulmonary exercise testing (see Fig. 2) both $C O$ and $S V$ could be accurately quantified. For non-invasive $C O$ estimation, exercise tests were performed on an electronically braked cycle ergometer or motor driven treadmill controlled by computer. Subjects were familiarized with the apparatus and performed a continuous incremental test with step vice increased workload up to the exhaustion for determination of $V O_{2 \max }, H R_{\max }$, blood pressure, anaerobic threshold etc. The expired gas samples were analyzed by $\mathrm{O}_{2}$ $\mathrm{CO}_{2}$ gas analyzer. All electrical signals from $\mathrm{HR}$ and volume sensors and from gas analyzer were processed in personal computer. From the measured values the $C O$ was estimated according formula $[11,12]$ :

$$
C O=\frac{100 * \mathrm{VO}_{2}}{\left[5.721+0.1047 \frac{100 * V O_{2}}{V O_{2 M A X}}\right]}
$$


The function $C O=f\left(V_{2}\right)$ according eq. (1) for $V \mathrm{O}_{2} \in[0.36]$ is shown in Fig. 1 .

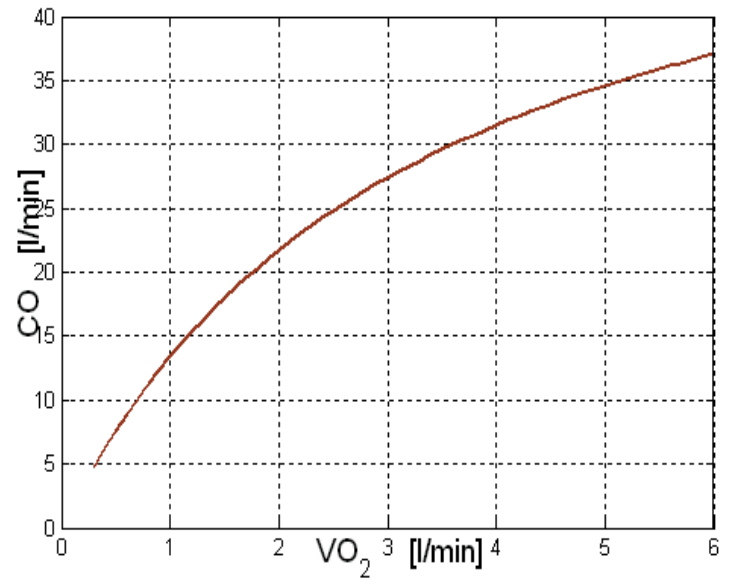

Figure 1. The graph of function $\mathrm{CO}$ versus $\mathrm{VO}_{2}$ for $\mathrm{VO}_{2} \in\left\langle\begin{array}{ll}0.3 & 6\rangle\end{array}\right.$. The $\mathrm{CO}$ is estimated from measured $\mathrm{VO}_{2}$, according eq. (1). The graph is calculated for $V O_{2 \mathrm{MAX}}=6[1 / \mathrm{min}]$



Figure 2. Photo of the subject running on treadmill

Measurements of $\mathrm{CO}$ and filling pressure provide information for "early diagnosis, monitoring of disease progression, and titration of therapy in heart failure, shock of any type, sepsis, and during cardiac surgery". If cardiac output could be controlled at more frequent intervals, or even continuously, clinicians could detect abnormalities in the cardiorespiratory system and provide appropriate interventions sooner. In this paper the non-invasive estimation method for $\mathrm{CO}$ and other parameters was used in group of twenty male marathon runners. Studies were done with the help of measuring system (including $\mathrm{O}_{2}-\mathrm{CO}_{2}$ gas analyzer) connected to personal computer and Lode treadmill ergometer (photo, see Fig. 2). A nonrebreathing valve was connected to a mouthpiece to prevent mixing of inspired and expired air [13 - 21]. The electrical signals from sensors were connected to microcontroller based measuring system.

\section{MATERIAL AND METHODS}

On the beginning for all 20 people, a short exercise test was first performed (Increased incremental load up to maximum, length of test approx. $16 \mathrm{~min}$ ) on treadmill. Example of the time evolution of measured and calculated parameters versus speed are shown in Fig. 3. From Fig. 3 is shown that measured and calculated parameters have almost same dynamics and therefore it is possible use simple mathematical model based on linear or nonlinear regression approach. Example of such model is shown in Fig. 4 where $C O$ versus $H R$ is derived as linear and cubic function. The same process was used also for other subjects. The examples of mathematical models for some subjects are presented in Tab. 1.

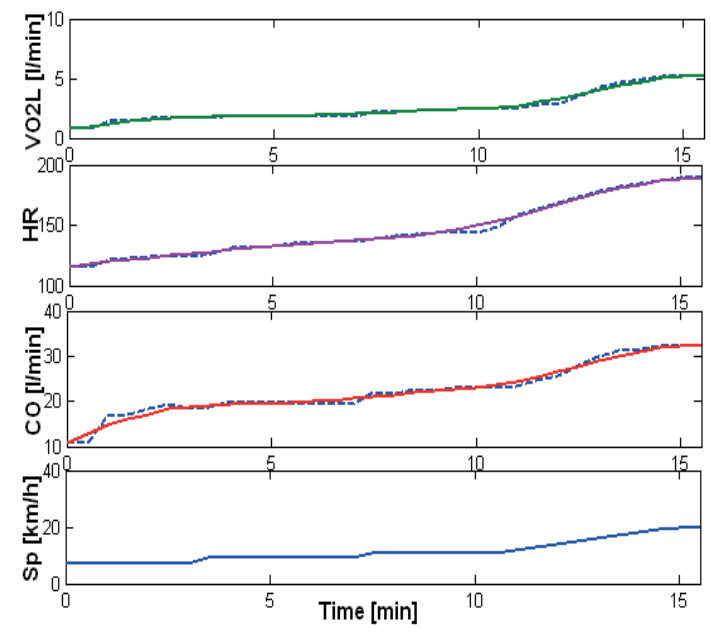

Figure 3. Time evolution of short exercise test. From top to bottom: $\mathrm{VO}_{2}, \mathrm{HR}, \mathrm{CO}$, speed of treadmill. Dash lines - measured, solid lines - smooth. Subject M1

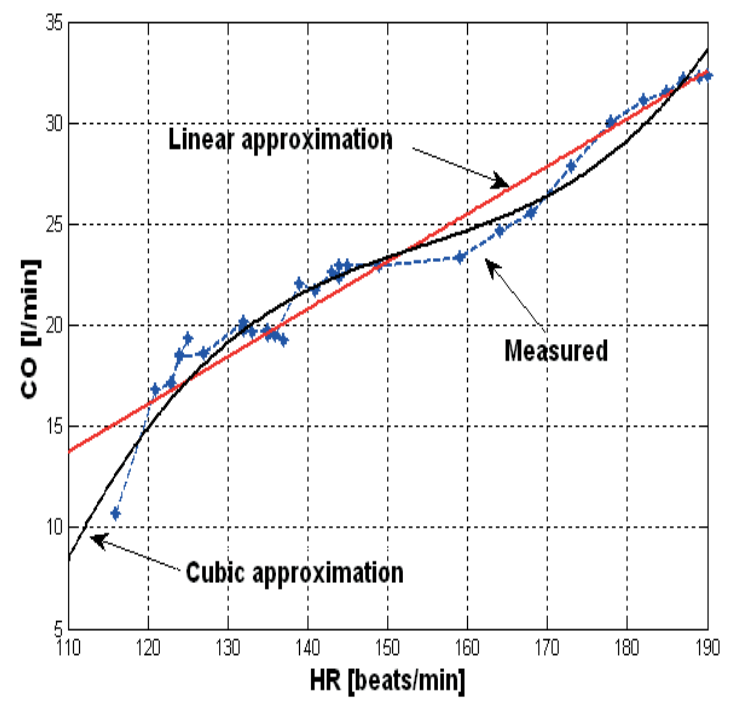

Figure 4. The relation $C O$ versus $H R$ from short exercise test on treadmill (16 min test), linear and cubic regression. Subject M1. Blue dash curve - measured, red - linear model, black - cubic model

The two models, linear and cubic are used for estimation of $C O$ from $H R$. Linear estimation $C O_{E I}$ is 


$$
C O_{E 1}=k_{1} H R+k_{2} \quad[1 / \mathrm{min}, \text { beats } / \mathrm{min}]
$$

where $k_{1}$ and $k_{2}$ are individual coefficients of subject.

Cubic estimation $\mathrm{CO}_{E 2}$ is given as

$$
\begin{aligned}
C O_{E 2} & =c_{1} H R^{3}+c_{2} H R^{2} \\
& +c_{3} H R+c_{4}
\end{aligned}
$$

where $c_{1}, c_{2}, c_{3}$ and $c_{4}$ are individual coefficients of subject.. The coefficient values of some subject are presented in Tab. I. $S V$ is given as:

$$
S V=1000 \cdot \frac{C O}{H R}[\mathrm{ml} / \text { beats, } 1 / \mathrm{min} \text {, beats } / \mathrm{min}]
$$

TABLE I. LINEAR AND CUBIC MATHEMATICAL MODELS CO AS FUNCTION OF HR FOR SOME SUBJECTS CALCULATED FROM SHORT EXERCISE

\begin{tabular}{|c|l|}
\hline Subject & Coefficients \\
\hline M1 & $k_{1}=0.24 ; k_{2}=-12$ \\
\hline M1 & $c_{1}=0.000111 ; c_{2}=-0.0515 ; c_{3}=8.1 ; c_{4}=-405$ \\
\hline M3 & $k_{1}=0.15 ; k_{2}=--5$ \\
\hline M3 & $c_{1}=6.89 \mathrm{e}-005 ; c_{2}=-0.0338 ; c_{3}=5.64 ; c_{4}=-301$ \\
\hline M6 & $k_{1}=0.21 ; k_{2}=-8.6$ \\
\hline M6 & $c_{1}=0.000231 ; c_{2}=-0.0916 ; c_{3}=12.2 ; c_{4}=-527$ \\
\hline M10 & $k_{1}=0.22 ; \cdot k_{2}=-4.7$ \\
\hline M10 & $c_{1}=0.000112 ; c_{2}=-0.05 ; c_{3}=7.52 ; c_{4}=-353$ \\
\hline
\end{tabular}

TABLE II.

SUBJECT CHARACTERISTIC $(\mathrm{N}=20)$. SUB - SUBJECT, M_CO - MEAN VALUE OF CARDIAC OUTPUT, M_SV - MEAN VALUE OF STROKE VOLUME (MEASURED DURING MARATHON RUN)

\begin{tabular}{lrrrrrr|}
\hline Sub & Age & Height & Weight & BMI & M_CO & M_SV \\
\hline M1 & 32 & 183.5 & 75.4 & 22.4 & 23.7 & 147.7 \\
M2 & 26 & 186 & 75.2 & 21.7 & 16.2 & 96.7 \\
M3 & 28 & 180 & 74 & 22.8 & 18.2 & 109.7 \\
M4 & 37 & 174.5 & 78.4 & 25.7 & 19.4 & 135.6 \\
M5 & 39 & 186 & 90.4 & 26.1 & 20.1 & 133.8 \\
M6 & 48 & 193 & 97.4 & 26.1 & 16.5 & 133.5 \\
M7 & 24 & 183 & 68 & 20.3 & 22.8 & 134.1 \\
M8 & 71 & 171.5 & 63 & 21.4 & 15.6 & 111.7 \\
M9 & 27 & 179 & 74.60 & 23.3 & 21.7 & 136.4 \\
M10 & 38 & 179 & 94 & 29.3 & 20.2 & 125.8 \\
M11 & 41 & 187 & 85.8 & 24.5 & 24.2 & 171.0 \\
M12 & 35 & 197 & 79.3 & 20.4 & 21.2 & 125.9 \\
M13 & 35 & 179 & 77.4 & 24.2 & 18.9 & 106.8 \\
M14 & 37 & 184 & 86.6 & 25.6 & 23.4 & 150.6 \\
M15 & 44 & 179 & 78.6 & 24.5 & 19.3 & 133.2 \\
M16 & 33 & 181.5 & 81.4 & 24.7 & 19.8 & 136.6 \\
M17 & 38 & 175 & 73 & 23.8 & 16.1 & 101.7 \\
M18 & 42 & 183.5 & 74.2 & 22.0 & 15.5 & 99.1 \\
M19 & 37 & 184.5 & 84.3 & 24.8 & 22.1 & 128.1 \\
M20 & 39 & 180 & 70 & 21.6 & 16.0 & 127.0 \\
Mean & $\mathbf{3 7 . 6}$ & $\mathbf{1 8 2 . 3}$ & $\mathbf{7 9 . 1}$ & $\mathbf{2 3 . 8}$ & $\mathbf{1 9 . 5}$ & $\mathbf{1 2 7 . 2}$ \\
SD & $\mathbf{1 0 . 0}$ & $\mathbf{6 . 0}$ & $\mathbf{8 . 7}$ & $\mathbf{2 . 2}$ & $\mathbf{2 . 9}$ & $\mathbf{1 8 . 7}$ \\
\hline
\end{tabular}

\section{RESULTS}

After a short period of time from the first short examination (approx. until 14 days), a long-term 2hour test was performed. The basic parameters of all 20 marathon runners are displayed in Tab. 2 including mean values and standard deviations. The one example of time evolution of parameters during marathon exercise is shown in Fig. 5. The short peak in the chart is caused by stopping for snacks (drink) or taking blood sample. Evolution of $S V$ and linear (regression) model is displayed in Fig. 6.
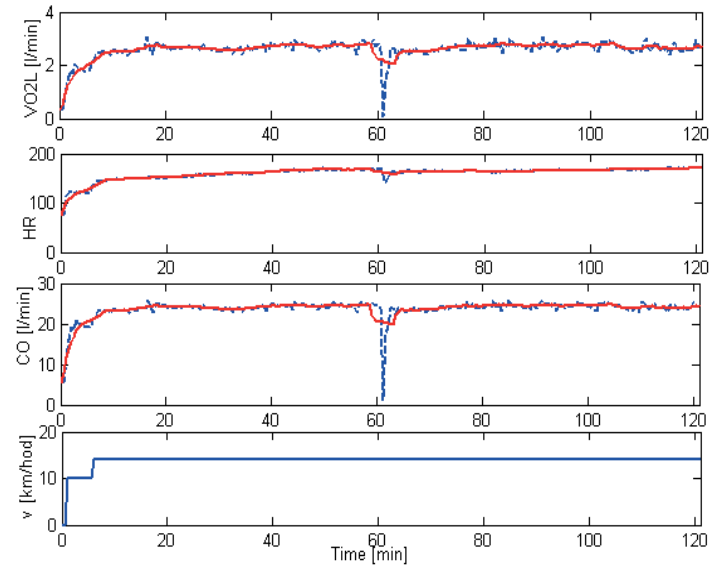

Figure 5. Subject M1, marathon exercise. From top to bottom: Time evolution of $\mathrm{VO}_{2}, \mathrm{HR}, \mathrm{CO}$ and speed of the treadmill. Blue (dash) - raw measured values, red (solid) - filtered values

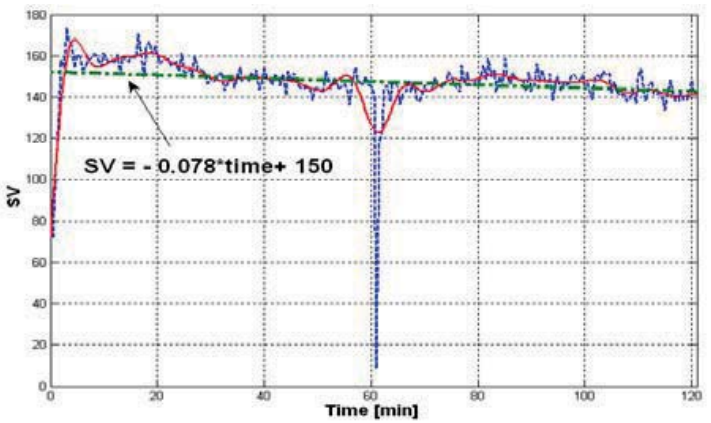

Figure 6. Subject M1, marathon exercise. SV time evolution (blue, dash line), smoothed SV (red, solid line) and linear approximation (green, dot-dash line) and equation

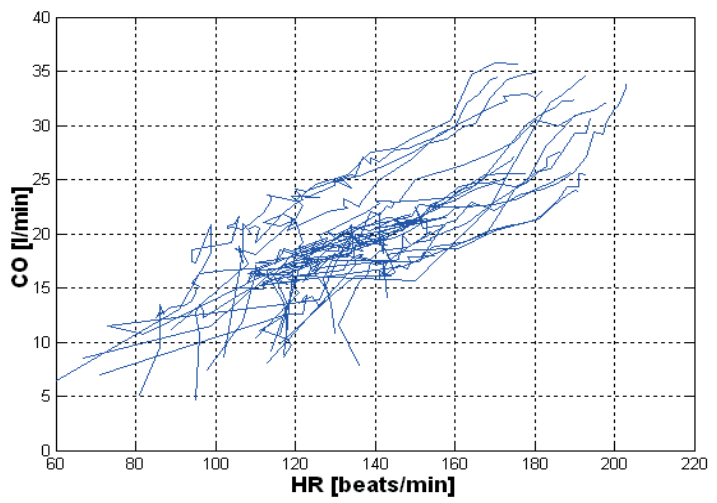

Figure 7. All Subject M1 to M20, $C O$ versus $H R$ measured from short examination 


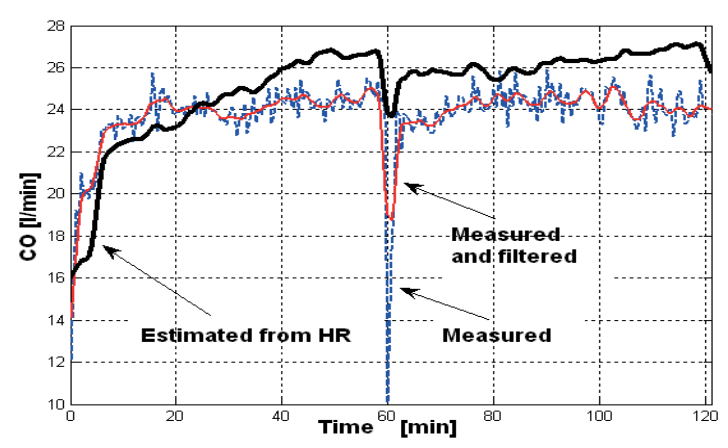

Figure 8. Subject M1, marathon exercise. $\mathrm{CO}$ derived from $\mathrm{VO}_{2}$ (blue - dash), $\mathrm{CO}$ derived from $\mathrm{VO}_{2}$-filtered (red-solid), $\mathrm{CO}$ estimated from $H R$ (black-solid) ( linear model)

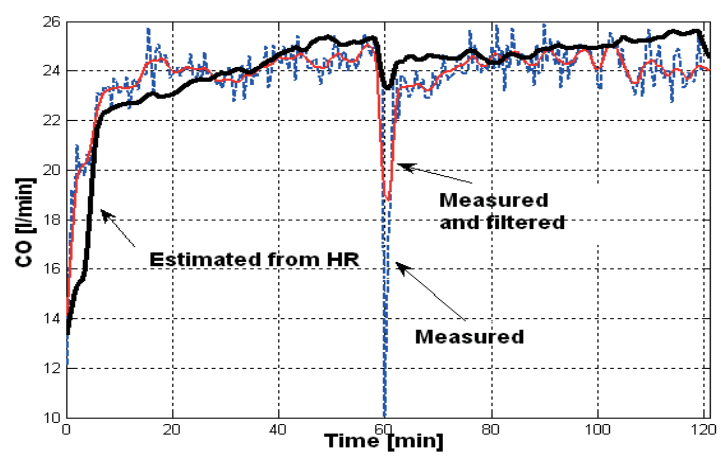

Figure 9. Subject M1, marathon exercise. $\mathrm{CO}$ derived from $\mathrm{VO}_{2}$ (blue - dash), $\mathrm{CO}$ derived from $\mathrm{VO}_{2}$-filtered (red-solid), $\mathrm{CO}$ estimated from $H R$ (black-solid) (cubic model)

The results of measuring of all 20 subjects $(C O$ versus $H R$ ) are presented in Fig. 7. In Fig. 8 the $C O$ estimation from $\mathrm{VO}_{2}$, filtered estimation from $\mathrm{VO}_{2}$ and estimation $C O$ based on linear model gained from relation $C O$ versus $H R$ according eq. (2) is shown. In Fig. 9 the estimation based on cubic model is displayed. From Fig. 8 and 9 can be seen that cubic model used for estimation of $C O$ is much better then linear model. Therefore $C O$ for different outdoor activities can be estimated from $H R$ if the mathematical model from short examination is known.

\section{DISCUSSION}

In this work the 20 marathon runners were tested and calculation of $\mathrm{CO}$ based on $\mathrm{VO}_{2}$ measuring was presented. From short examination for increased load up to maximum, the linear and cubic mathematical models $C O$ versus $H R$ were derived. This models was used for estimation $C O$ during marathon from $H R$. The result shows good match between measuring and models, but nonlinear - cubic model is better. The main advantage of the estimation $C O$ from $H R$ is that if the mathematical model $C O$ versus $H R$ was derived the $C O$ can be estimated for outdoor activities only from $H R$ measuring.

\section{REFERENCES}

[1] A. C. Guyton and J.E. Hall. Textbook of Medical Physiology. Saunders and Company, 11th edition, 2005.

[2] T. Heldt. "Continuous blood pressure-derived cardiac output monitoring -should we be thinking long term?" Journal of Applied Physiology, 101(2):373, 2006.
[3] L. K. Hill et al, "Evaluation of a simple estimation method for the derivation of cardiac output from arterial blood pressure and heart rate," Biomed Sciences Instrumentation 48, 2011, pp. 165-170.

[4] K. H Wesseling, J. R. Jansen, J. J. Settels, et al., "Computation of aortic flow from pressure in humans using a nonlinear, three-element model,". J Appl Physiol; 74(5):2566-2573; 1993.

[5] K. C. Beck, L. N. Randolph, K. R. Bailey, C. M. Wood, E. M. Snyder and B. D. Johnson, "Relationship between cardiac output and oxygen consumption during upright cycle exercise in healthy humans," J Appl Physiol. 101: pp. 1474-1480, 2006.

[6] Ylva Hellsten and Michael Nyberg, "Cardiovascular Adaptations to Exercise Training," Comprehensive Physiology, Cardiovascular Effects of Endurance Training, Volume 6, January 2016.

[7] M. Harold Laughlin, "Cardiovascular Response to Exercise," American journal of physiology, January 2000.

[8] D. E. Lieberman and D. M. Bramble, "The evolution of marathon running: capabilities in humans," Sports Medicine, vol. 37, no. 4-5, pp. 288-290, 2007.

[9] V. L. Billat, H. Petot, M. Landrain, R. Meilland, J. P. Koralsztein, and L. Mille-Hamard, "Cardiac Output and Performance during a Marathon Race in Middle-Aged Recreational Runners," The ScientificWorld Journal Volume 2012, doi:10.1100/2012/810859..

[10] M. J. Joyner, "Modeling: optimal marathon performance on the basis of physiological factors," Journal of Applied Physiology, vol. 70, no. 2, pp. 683-687, 1991.

[11] W. W. Stringer, J. E. Hansen, and K. Wasserman, "Cardiac output estimated noninvasively from oxygen uptake during exercise," J. Appl. Physiol. 82(3): 908-912, 1997.

[12] K. Wasserman, J. E. Hansen, D. Y. Sue, B. J. Whipp and R. Casaburi, "Principles in exercise testing and interpretation," Principles in Exercise Testing and Interpretation. Philadelphia, PA: Lea \& Febiger, 1994.

[13] M. B. Maron, S. M. Horvath, J. E. Wilkerson, and J. A. Gliner, "Oxygen uptake measurements during competitive marathon running," Journal of Applied Physiology, vol. 40, no. 5, pp. 836-838, 1976.

[14] V. L. Billat, "The occurrence of a VO2 drop after the achievement of a VO2 peak or VO2max plateau," Journal of Applied Physiology, vol. 104, no. 1, pp. 283-285, 2008.

[15] J. E. McLaughlin, G. A. King, E. T. Howley, D. R. Bassett, and B. E. Ainsworth, "Validation of the COSMED K4 b2 portable metabolic system," International Journal of Sports Medicine, vol. 22, no. 4, pp. 280-284, 2001.

[16] R. Richard, E. Lonsdorfer-Wolf, A. Charloux et al., C. Vignatil and G. Cattadori, "Measuring Cardiac Output during Cardiopulmonary Exercise Testing," Ann Am Thorac Soc Vol 14, Supplement 1, pp. S48-S52, Jul 2017.

[17] C. C. Lang, P. Karlin, J. Haythe, L. Tsao, D. M. Mancini. "Ease of noninvasive measurement of cardiac output coupled with peak VO2 determination at rest and during exercise in patients with heart failure," Am J Cardiol. 99:404-405, 2007.

[18] G. Cattadori, E. Salvioni, E. Gondoni, P. Agostoni, "Evaluation of noninvasive exercise cardiac output determination in chronic heart failure patients: a proposal of a new diagnostic and prognostic method," J Cardiovasc Med (Hagerstown) 2011.

[19] V. Unnithan, T.W. Rowland, "Use of oxygen pulse in predicting Doppler derived maximal stroke volume in adolescents,". Pediatr Exerc. Sci.;2 7:412-418, 2015

[20] M. R. Zenger, M. Brenner, M. Haruno,, D. Mahon, A. F. Wilson, "Measurement of cardiac output by automated singlebreath technique, and comparison with thermodilution and Fick methods in patients with cardiac disease," Am J Cardiol; 71:105-109, 1993.

[21] P. Agostoni, C. Vignati, P. Gentile, C. Boiti, S. Farina, E. Salvioni, M. Mapelli, D. Magrı, S. Paolillo, N. Corrieri, et al., "Reference values for peak exercise cardiac output in healthy individuals," Chest;pii: S0012-3692(17)30020-X, 2017. 